\title{
The Migration of Olfactory Ensheathing Cells during Development and Regeneration
}

\author{
Jenny A.K. Ekberg Daniel Amaya Alan Mackay-Sim James A. St. John \\ Eskitis Institute for Cell and Molecular Therapies, Griffith University, Brisbane, Qld., Australia
}

\section{Key Words}

Neuron $\cdot$ Axon $\cdot$ Glia $\cdot$ Neurite outgrowth $\cdot$ Regeneration

\begin{abstract}
The primary olfactory nervous system is unique in that it continuously renews itself and regenerates after injury. These properties are attributed to the presence of olfactory glia, termed olfactory ensheathing cells (OECs). Evidence is now emerging that individual OEC populations exist with distinct anatomical localisations and physiological properties, but their differential roles have not been determined. Unlike other glia, OECs can migrate from the periphery into the central nervous system, and organised OEC migration can enhance axonal extension after injury. Despite this, the mechanisms regulating OEC migration are largely unknown. Here, we provide an overview of the roles of OECs in development and adulthood. We review the latest research describing the differences between individual OEC subpopulations and discuss potential regulatory mechanisms for OEC guidance and migration. Using advanced time lapse techniques, we have obtained novel insights into how OECs behave in a complex multicellular environment which we discuss here with particular focus on cell-cell interactions. Significantly, transplantation of OECs constitutes a promising
\end{abstract}

novel therapy for nerve injuries, but results are highly variable and the method needs improvement. We here review the roles of transplanted OECs in neural repair of damaged neuronal tracts distinct from the primary olfactory nervous system.

Copyright $\odot 2012$ S. Karger AG, Basel

\section{Introduction}

The olfactory system is perhaps the most plastic part of the adult nervous system. Throughout development and adult life, neurogenesis continues to occur in the olfactory epithelium in the nose where stem cells in the basal layer of the epithelium proliferate to generate new sensory neurons [1-3]. In normal healthy adult animals, when the neurons reach the end of their lifespan of 1-3 months [3], they undergo apoptosis and are replaced by new neurons originating from progenitors in the nasal mucosa. Thus, $1-3 \%$ of olfactory neurons turn over daily. An injury or infection of the olfactory system can lead to apoptosis of the sensory neurons in the epithelium. Several studies, including investigation of neuronal turnover in the primate olfactory nervous system $[4,5]$, have demonstrated that after injury or infection the dead neurons

Dr. James A. St. John

Eskitis Institute for Cell and Molecular Therapies Griffith University, 170 Kessels Road

Nathan, Brisbane, QLD 4111 (Australia)

Tel. +61 73735 3660, E-Mail j.stjohn@griffith.edu.au 


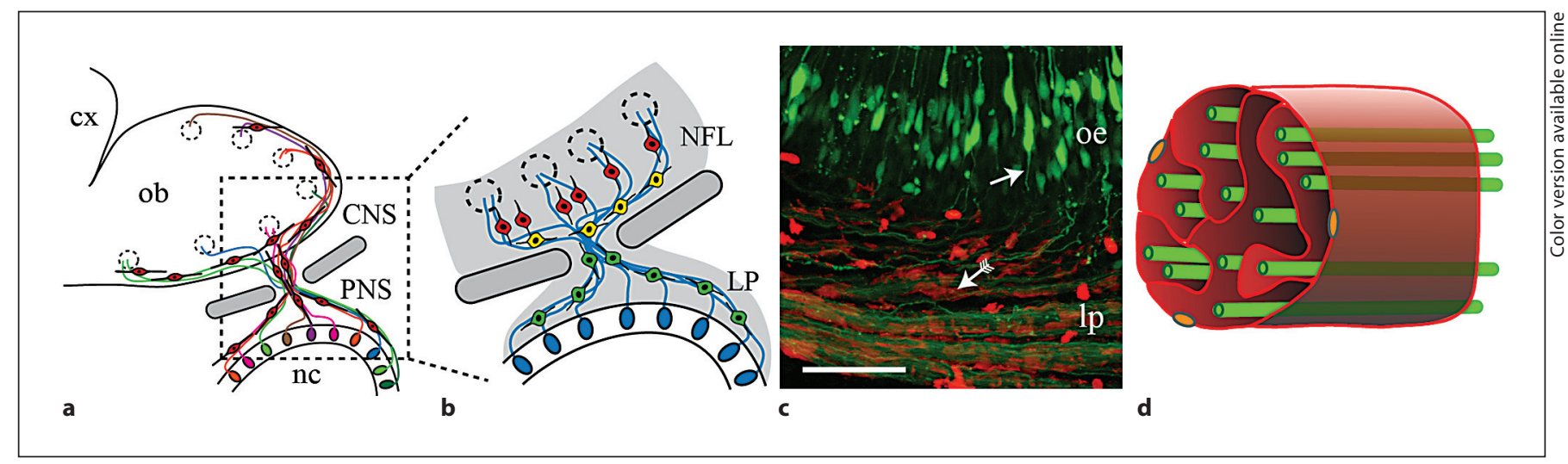

Fig. 1. Subpopulations of OECs fasciculate primary olfactory axons. a Schematic of the olfactory system. Olfactory axons project from the olfactory epithelium lining the nasal cavity (nc) to the olfactory bulb (ob), with OECs surrounding the axons in all regions. Rostral to the right and dorsal to the top. $\mathrm{cx}=$ Cortex; PNS = peripheral nervous system; CNS = central nervous system. b OECs in the lamina propria (LP) contribute to fasciculation of axons, OECs in the outer layer of the nerve fibre layer (NFL) con- tribute to defasciculation, and OECs in the inner layer of the NFL contribute to sorting and targeting of axons. c Primary olfactory neurons within the olfactory epithelium (oe) send their axons (arrow) into the lamina propria (lp) where bundles of axons are wrapped up by OECs (arrow with tail). Scale bar $=50 \mu \mathrm{m}$. d Schematic of an axon fascicle with several OECs surrounding numerous axons. are rapidly replaced via enhanced neurogenesis. The remarkable ability for continual axon growth and successful topographic targeting in the primary olfactory nervous system is attributed to the presence of a specialised type of glial cells, olfactory ensheathing cells (OECs), that are thought to be crucial for the survival and growth of primary olfactory neurons [6]. In fact, it has been proposed that the guidance of pioneer axons and the establishment of the olfactory nerve tracts are ultimately orchestrated by OECs [7].

Primary olfactory neurons are born in the nasal epithelium and extend their axons all the way to the olfactory bulb within the brain. OECs are unique amongst glia in that they can migrate from the peripheral nervous system into the central nervous system; together with the extending olfactory axons, OECs migrate from the nasal epithelium and into the olfactory bulb. Thus, olfactory axons are constantly in close contact with OECs en route to the bulb (fig. 1a-c). In contrast to other types of glia such as peripheral Schwann cells, OECs do not myelinate olfactory axons. Instead OECs encase large bundles of numerous unmyelinated axons rather than ensheathing individual axons (fig. 1d) [8]. The topographic projections of the olfactory sensory axons is highly complex such that each neuron within the olfactory epithelium expresses one of approximately 1,200 odorant receptors with the neurons being mosaically distributed throughout the epithelium [9]. The axons project in mixed bun- dles to the outer layer of the olfactory bulb without maintaining near-neighbour relationships. Upon entering the nerve fibre layer (NFL) the axons defasciculate, sort out and then refasciculate so that axons from neurons that express the same odorant receptor come together prior to targeting to their topographically appropriate glomerulus (fig. 1a) [10]. As OECs are intimately associated with the axons during all stages of the axon guidance processes (fig. 1a, b), they are likely to contribute to the defasciculation, sorting and refasciculation of axons in the NFL and are therefore considered to be crucial to the successful establishment of the olfactory topographic map $[8,11]$.

The OECs have properties that are thought to underlie the unique ability of the peripheral olfactory nervous system to continuously regenerate itself, and allow olfactory sensory axons to constantly breach the border between the peripheral and central nervous systems. It is for these reasons that transplantation of OECs to injury sites in other regions of the nervous system are being trialled for neural repair therapies. While there have been some very promising results, the neuro-anatomical and functional outcomes are variable, and improvements need to be achieved before effective therapies are developed for humans. While the mechanisms regulating axon guidance in the olfactory system have been studied in detail, surprisingly little is known about the molecular and cellular mechanisms that regulate the guidance and cell-cell in- 
teractions of OECs. Determining the molecular and cellular mechanisms by which OECs regulate axonal behaviour will lead to a better understanding of the role of OECs in development and regeneration within the olfactory system and will identify how the use of OECs can be optimised for neural regeneration therapies.

\section{Origin of OECs and Population of the Olfactory Nerve}

During early development, OEC precursors arise from the neural crest and populate the olfactory placode $[12$, 13]. In the mouse, the olfactory epithelium forms from the cranial ectoderm and specialised placodes, and is easily detected by embryonic day 10 (E10) [14]. The olfactory placodes then invaginate to form the olfactory pits which give rise to the primary olfactory epithelium lining the nasal cavity [14]. In these epithelia, olfactory sensory neurons are generated. Their pioneer sensory axons leave the nasal pit and then extend dorsally through the frontonasal mesenchyme to the telencephalon [15]. Axons extending towards the central nervous system are accompanied by a heterogeneous population of cells including OECs [11]. By E11.5, fascicles of intermingled axons expressing different odorant receptors coalesce to form the olfactory nerve, with each fascicle consisting of numerous axons encased by OECs (fig. 1b, d) [15]. The OECs are thought to promote axon growth by providing a cellular substrate containing molecules that facilitate axonal adhesion and extension and by expressing growth-promoting agents such as brain-derived neurotrophic factor, glia-derived nexin and nerve growth factor [16-21]. Indeed, OECs always extend processes ahead of the pioneer olfactory axons they ensheathe, and thus it would appear that the growth of olfactory axons is reliant on the OECs [22-24]. This is in contrast to Schwann cells which migrate along already defined axonal pathways during development of the peripheral nervous system [25].

At E13, the olfactory sensory axons together with the OECs fuse with the outer surface of the telencephalon which stimulates it to form the presumptive olfactory bulb $[11,26]$. Olfactory axons and OECs then extend across the surface of the presumptive bulb to form the NFL, with the OECs forming a single layer directly apposed to the astrocytic glia limitans [11,24]. To maintain their ensheathment of the increasing number of olfactory axons, OECs proliferate rapidly and develop highly elaborate processes [24]. At this stage, the NFL has developed to contain 2 layers defined as the inner and the outer
NFL. Primary sensory axons remain in the outer NFL for 2-3 days during which axons defasciculate from their intermixed bundles in the olfactory nerve and commence sorting out so that axons from neurons that express the same odorant receptor condense together (fig. 1a, b) [27]. The axons then extend towards their targets and sort out such that axons from neurons that express the same odorant receptor come together and refasciculate with other axons expressing the same odorant receptor type [10]. This refasciculation occurs in the inner NFL. The newly formed fascicles of axons of the same odorant receptor type then project to their appropriate glomerulus in the glomerular layer, where the axons synapse onto secondorder neurons. Within the outer NFL, the OECs are thought to contribute to the defasciculation of the mixed bundles of axons, whereas within the inner NFL the OECs are thought to facilitate the sorting and refasciculation of axons of the same odorant receptor type (fig. 1b). Thus, the OECs in the peripheral region are likely to contribute to adhesion and fasciculation of the axons, whereas the OECs within the NFL are likely to contribute to the complex sorting of axons [28].

\section{OECs Are a Heterogeneous Population of Cells}

While OECs are thought to have a common peripheral origin, evidence is now emerging demonstrating that individual subpopulations of OECs exist with distinct anatomical localisation, behaviour and expression pattern of certain molecules. OECs in the peripheral olfactory nerve express several molecules (including CD44, Notch 3, chondroitin sulphate proteoglycan NG2, vascular endothelial growth factor, $\beta_{1}$-integrin) that are not expressed by OECs from the NFL of the olfactory bulb [29]. While several molecules are considered to be markers of OECs, they are not necessarily universally expressed by OECs. For example, OECs that populate the peripheral olfactory nerve and the outer layer of the NFL express S100ß and p75 neurotrophin receptor (p75ntr), whereas OECs of the inner NFL express low or negligible levels of S100ß and do not express p75ntr at all $[28,30]$. In addition, the OECs of the inner NFL express neuropeptide Y, whereas the OECs of the outer NFL do not [31].

Significantly, some molecules that differ in their expression between OEC subtypes are those that are proposed to contribute to axon guidance. Within the NFL, OECs differentially express galectins 1,3 and $4, \beta_{2}$-laminin and the chemorepulsive factor semaphorin $3 \mathrm{~A}$ (Sema3A) [32-34], which all are classical axon guidance 
regulators. The subpopulation of olfactory sensory axons that expresses the Sema3A receptor, neuropilin 1, is repelled from the OECs that express Sema3A, while the subpopulation of axons that expresses lactosamine-containing glycans converges on the region containing OECs that express high levels of Sema3A, galectin 1 and $\beta_{2}$ laminin $[32,33]$. In addition, two subpopulations of OECs within the NFL as a whole have been identified based on their electrophysiological profiles with the differences being attributed to the gap junction connectivity of the cells [35].

Further complicating our understanding of the differences of the subpopulations of OECs is the fact that the NFL is not a uniform structure but varies considerably with the anatomical location. The rostral and ventral NFL is relatively thick with distinct inner and outer layers, whereas the NFL in the dorsal and caudal regions of the olfactory bulb is thin and without the clear layers. Most of the defasciculation and sorting of axons occurs when the axons first enter the NFL in the rostral and ventral olfactory bulb $[26,28]$; axons in the dorsal and caudal NFL are largely already sorted and project directly to their target glomeruli [36] (fig. 1a). Further, the olfactory bulb develops in a rostral-caudal gradient with the rostral regions developing first. For example, P2 odorant receptor glomeruli which are located in the ventral and rostral halves of the olfactory bulb develop from E18 onwards $[10,27]$, whereas the M72 odorant receptor glomeruli which are located in the dorsal and caudal halves of the olfactory bulb develop from postnatal day 3 onwards in the mouse [37]. Thus, the NFL is not a uniform structure, and OECs within the different regions are likely to have different functions particularly during development.

Using a line of fluorescent reporter transgenic mice, S100ß-DsRed mice, in which glial cells express the fluorescent protein DsRed, we have recently purified subpopulations of OECs to assess their behaviour $[38,39]$. We compared peripheral OECs and central OECs (containing OECs from both the inner and outer NFLs) as it is technically very difficult to separate the inner and outer NFL. We found that OECs from the peripheral olfactory nerve predominantly adhere to each other and migrate close together, whereas OECs from the NFL of the olfactory bulb display a mix of adhesion, repulsion or no response, and are only loosely associated. These findings are consistent with the proposed role of OECs in vivo: cell-cell adhesion between peripheral OECs would lead to formation of axon fascicles surrounded by OECs, whereas the mixed behaviour displayed by central OECs possibly reflects complex sorting. We also further confirmed that within the central OEC population that OECs derived from different parts of the bulb displayed different proportions of adhesion, repulsion and no response during cell-cell interactions [39] which is also consistent with the proposed roles of OECs in vivo. For example in the rostral region of the NFL, axons undergo extensive sorting, whereas in the dorsal/caudal region of the NFL axons have largely already been sorted and are projecting to their targets. OECs from the rostral NFL displayed an even mix of adhesion, repulsion and no response consistent with their contribution to axon sorting, whereas OECs in the caudal NFL displayed predominantly adhesion responses consistent with their role in axon fasciculation [39]. We also noted functional differences in the OECs from the olfactory bulbs of embryonic, postnatal and adult olfactory bulbs. Thus, it is clear that OECs are not a uniform population of cells but instead consist of at least 3 subpopulations each with distinct molecular expression profiles and behavioural differences during cellcell contact. This is consistent with the proposed roles of the subpopulations of OECs in the guidance of olfactory sensory axons [39]. To study the behaviour of olfactory neurons in the presence of different subpopulations of OECs, we developed a mouse model in which primary olfactory neurons express the fluorescent protein ZsGreen (OMP-ZsGreen mice) [40]. We found that the presence of OECs is essential for growth of primary olfactory neurons in vitro (fig. 2a-c) [41]. Importantly, we showed that olfactory neurons behaved differently when cocultured with peripheral and central OECs. In the presence of peripheral OECs, axons formed fascicle-like structures (fig. 2d). In contrast, when cocultured with central OECs, axons extended in a dispersed manner (fig. 2d) [39]. Again, these results support the proposed in vivo roles of peripheral OECs mediating fasciculation and central OECs mediating defasciculation/sorting.

OECs also show heterogeneity when growing in vitro with two morphologies being particularly distinct, a bipolar Schwann-cell-like phenotype or a flattened astrocyte-like phenotype (fig. 3a, b), although tripolar and multipolar cells can also occur depending on growth conditions [42]. The bipolar OECs tend to have a single leading process and a trailing process (fig. $3 \mathrm{a}$ ). In contrast, flattened OECs tend to have a large membrane protrusion from one or both sides (fig. 3b). The bipolar OECs have been shown to migrate 3 times faster than the flattened OECs [43] so morphology may reflect a different functional state. It is now established that this heterogeneity is reflective of plasticity in morphology and molecular expression that can be manipulated by growth 

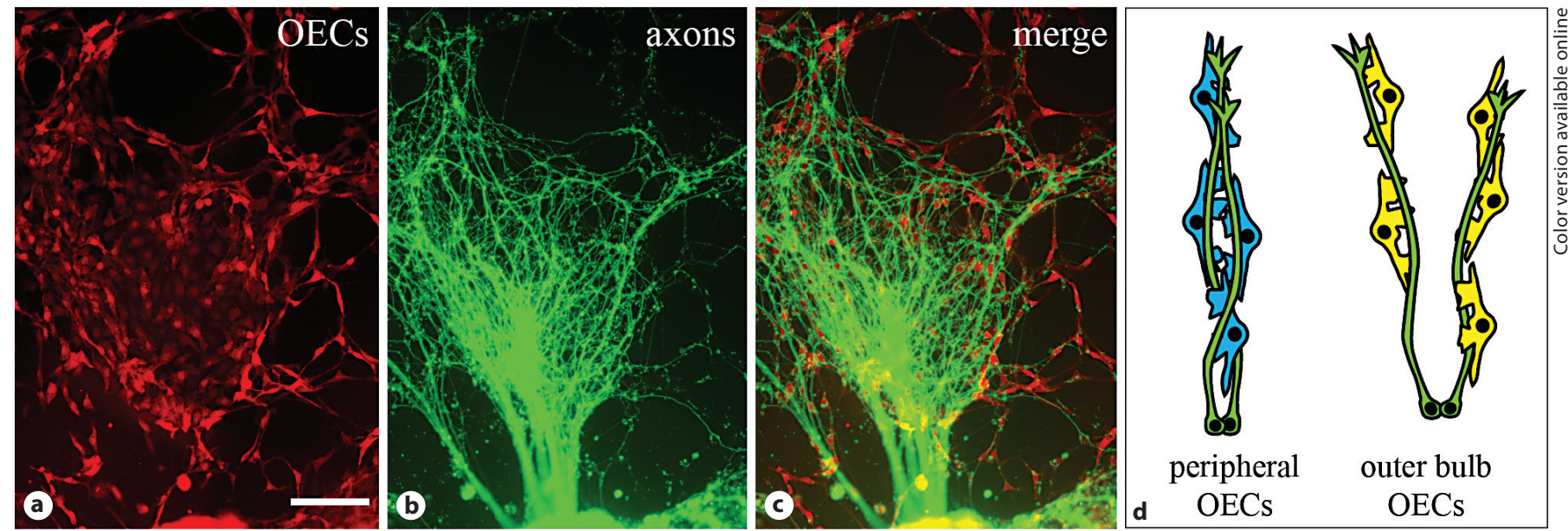

Fig. 2. OEC growth influences olfactory axon growth. When an explant of olfactory epithelium tissue is plated onto OECs (a), the axons grow out from the explant over the surface of the OECs (b). The axons clearly stay restricted to regions where the OECs are located (c). Scale bar $=40 \mu \mathrm{m}$. d The OEC subpopulation influences axon growth. OECs from the peripheral nerve aid fasciculation of axons, whereas OECs from the outer NFL of the olfactory bulb lead to defasciculation and sorting of axons.
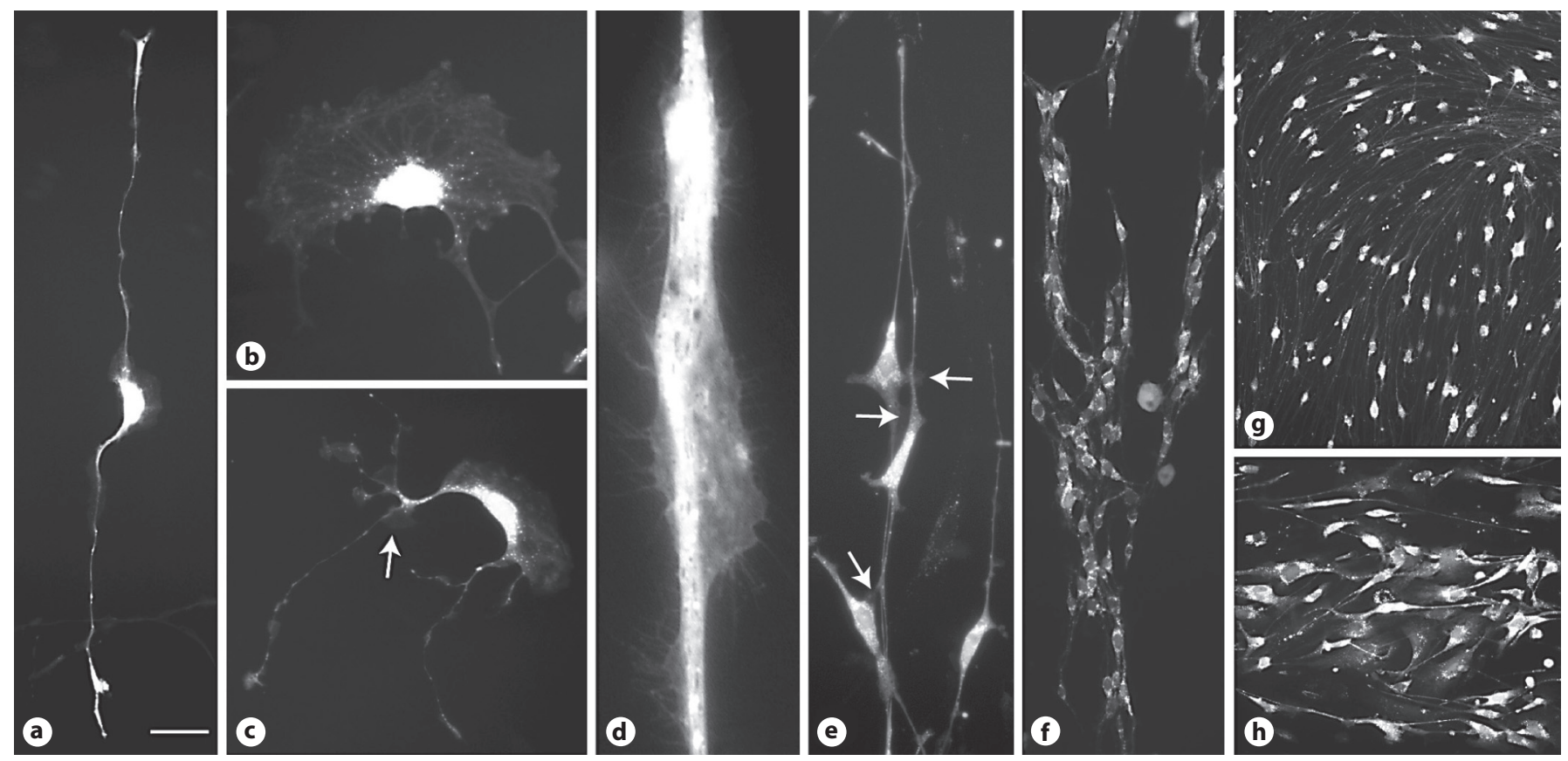

Fig. 3. OEC morphology and growth alter in vitro. Panels show OECs derived from the peripheral olfactory nerve. OECs can adopt a bipolar (a) or flattened (b) phenotype and can switch (c) between the two morphologies. Motile lamellipodial waves (arrow in c) are present on live cells, and fine filopodia (d) project from the lamellipodial waves. e Bipolar OECs initiating contact-mediated migration; arrows point to lamellipodial waves initiating contact between the cells. $\mathbf{f}$ Chains of bipolar OECs. $\mathbf{g}$ A uniform mass of bipolar OECs with directional migration. $\mathbf{h}$ A mix of bipolar and flattened OECs forms a mass of tissue. Scale bar $=20 \mu \mathrm{m}$ in $\mathbf{a}-\mathbf{c}, \mathbf{e}$, $4 \mu \mathrm{m}$ in $\mathbf{d}, 60 \mu \mathrm{m}$ in $\mathbf{f}, \mathbf{h}, 180 \mu \mathrm{m}$ in $\mathbf{g}$. 
conditions $[43,44]$. When monitored with time lapse imaging, cells of each morphology are seen to change into the other during the course of an hour $[43,45]$, and OECs can often be observed which appear to have both bipolar and flattened characteristics at the same time (fig. 3c). However, the morphological changes have not been examined for each different subpopulation of OECs. Thus, when examining the role of potential guidance cues on OECs, it is crucial that we consider the effect at the cellular level for each separate subpopulation of OECs.

\section{Regulation of OEC Migration at a Molecular Level}

Although it is readily established that OECs migrate from the nasal epithelium to populate the olfactory nerve, very little is known about the regulation of OEC migration. Only 4 factors have been identified to functionally modulate OEC migration, 3 of which are known modulators of axonal extension (glial derived neurotrophic factor, GDNF, Nogo-66 and Slit-2) [46-48], and 1 extracellular matrix protein, fibulin 3 [49]. Because OECs are regarded as such important regulators of axon growth and guidance, and particularly since we have recently shown that an increased OEC migration rate leads to enhanced axon growth [22], a clear characterisation of how migration of OECs is regulated is also interesting from a clinical perspective.

The first factor identified to modulate migration of OECs was GDNF [46]. OECs express and secrete GDNF [21], which is believed to constitute one of the mechanisms by which OECs promote axonal growth and neuronal survival. Significantly, genetically engineered OECs which express enhanced levels of GDNF have been found to be superior to wild-type OECs in their ability to promote axonal extension [50]. However, the mechanism by which GDNF promotes axon extension is more complicated than merely GDNF acting on receptors expressed by the neurons. OECs also express GDNF receptors, and it appears that some of the beneficial effects on axon extension may occur via GDNF stimulating OEC migration which subsequently enhances axon extension $[46,50]$. More recently, GDNF was found to regulate OEC migration via GDNF family receptor $\alpha_{1}$ and Ret receptors, and activation of JNK and Src intracellular signalling cascades [46]. We have demonstrated that on a cellular level, GDNF acts by stimulating the activity of peripheral lamellipodial waves which bear numerous fine filopodia (fig. 3c, d) [38], resulting in increased cell-cell contact and subsequent contact-dependent migration. While contact between OECs appears to stimulate migration, increased adhesion to extracellular matrix proteins has the opposite effect. A classical inhibitor of axonal extension, Nogo-66, has been shown to increase the adhesion of OECs to the extracellular matrix, resulting in a significantly decreased migration rate [48]. Nogo-66 acts on the $\mathrm{Ng}$ receptor, which is expressed in OECs [48] and also requires the coreceptor p75ntr [51]. It was recently demonstrated that OECs share a key characteristic with olfactory sensory neurons: both cell types express the Robo receptor for the repulsive guidance cue Slit-2 [47]. A gradient of Slit-2 in front of migrating OECs was shown to not only inhibit OEC migration, but also caused a collapse of the leading edge resulting in the complete reversal of migration direction. These effects were dependent on $\mathrm{Ca}^{2+}$ release from intracellular stores through inositol-1,4,5-triphosphate receptor channels. Specifically, the collapse of the leading edge required activation of the F-actin-depolymerizing protein cofilin in a $\mathrm{Ca}^{2+}$-dependent manner, whilst the reversal in migration direction was dependent on RhoA kinase activity.

It has been proposed that OECs may have a role in stimulating axogenesis in both the developing and mature olfactory system as they ensheathe growth cones immediately prior to their emergence from the olfactory epithelium [23]. In addition to GDNF, Nogo and Slit-2, OECs produce numerous putative neuritogenic factors such as PN-1, AAP, L1 and bone morphogenetic protein 7 [52-55]. It is possible that like GDNF, many guidance factors produced by OECs may regulate both axonal extension and OEC migration. These include classical neurotrophic/axonal guidance factors that show potential to regulate OEC migration, such as nerve growth factor, brain-derived neurotrophic factor, neurotrophin $4 / 5$, ciliary neurotrophic factor and vascular endothelial growth factor $[16,21,29,56,57]$. OECs also express receptors for many of these growth factors and other molecules [56], including the neurotrophin receptors, Trks and p75ntr $[29,58]$, ciliary neurotrophic factor receptor $\alpha$ [57], fibroblast growth factor receptor 1 [59], neuregulin receptors erbB1,2 [58], and others such as the hepatocyte growth factor receptor c-Met [60]. The role of the majority of these molecules has not been characterised for OECs within the olfactory system.

Within the peripheral nerve tract, OECs ensheathe olfactory axons in large bundles and extend cytoplasmic processes internally to compartmentalise the bundles (fig. 1d) [8]. OEC processes form conduits [61] that express a range of extracellular matrix proteins of which many are involved in cell adhesion $[15,32,53]$. One ex- 
tracellular matrix protein has been shown to directly regulate the migration of OECs: the $\mathrm{Ca}^{2+}$-binding glycoprotein fibulin 3 [49]. Viral-mediated overexpression of fibulin 3 in OECs inhibited OEC migration and instead promoted OEC proliferation. This also resulted in a decrease in neurite outgrowth of cocultured dorsal root ganglion neurons in comparison to control OECs, further supporting the hypothesis that OEC migration stimulates axonal extension. Furthermore, overexpression of fibulin 3 resulted in a decreased ability of OECs to integrate with other cell types. One of the properties that makes OECs such an attractive candidate for transplant therapies in comparison to other glia, such as Schwann cells, is their ability to freely associate with other cell types, such as astrocytes [62]. Thus, it is also crucial to characterise potential mechanisms that specifically regulate this behaviour. In addition to fibulin 3, OECs express a variety of cell adhesion proteins that potentially may regulate their migration, guidance and interactions with other cells, including embryonic neural cell adhesion molecule, L1, galectin $1, \beta_{2}$-laminin, collagen IV and $\mathrm{N}$ cadherin $[15,32,53,63]$.

Most of the studies described above have regarded OECs as a single population of cells. As discussed earlier, it appears that several individual OEC subpopulations with distinct characteristics and expression of key receptors for classical guidance cues coexist in the primary olfactory nervous system. Thus, a systematic comparison of migration and guidance regulation of the different subpopulations is highly warranted. Since only certain subpopulations of OECs express p75ntr, Nogo-mediated inhibition of migration is an example of a regulatory mechanism that may affect individual OEC subpopulations differently. Furthermore, it appears that OECs in the NFL of the olfactory bulb display differences in their expression of the receptor Wnt-4 [64]. While the functional significance of Wnt signalling in OECs remains unknown, in axons these pathways alter growth cone morphology and axonal extension. Thus, it is possible that individual subpopulations of OECs may display differential responses to a variety of factors.

\section{Regulation of OEC Migration at a Cellular Level}

Traditionally, cell migration has thus far been attributed mainly to the activity of the leading edge searching its environment, establishing adhesion followed by movement of the cell body and retraction of the cell rear [65, 66]. Using S100ß-DsRed OECs which fluoresce brightly red, we have studied the behaviour of the cells using highresolution time lapse microscopy. We made a breakthrough discovery in finding that OECs display highly motile lamellipodial protrusions along the shaft and cell body (fig. 3d), which significantly increase the migration of peripheral OECs in vitro [38]. These lamellipodial waves primarily induced cell-cell adhesion between peripheral OECs, which did not occur without initial wave contact. Thus, it appears that lamellipodial waves act to induce contact-stimulated migration of OECs. As discussed earlier, GDNF can stimulate OEC migration [46]. Significantly, we found that GDNF enhanced both the size and number of lamellipodial waves resulting in a 2 -fold increase in migration rate [38]. Cells with the potential for migration can increase their migration rate up to 200 -fold following contact with dense populations of migrating cells [67]. OECs migrate from the neuro-epithelium to the NFL while in close contact with each other and with primary olfactory axons, and it is consistent that adhesion induced by lamellipodial waves may result in contact-stimulated migration. We also showed that specific inhibition of MAPK/extracellular signal-regulated kinase (MEK), which acts downstream of GDNF as part of the Ras/Raf/MEK/ERK signalling pathway, blocked peripheral wave activity while leaving the leading edge intact. These data demonstrate that in OECs, the activity of peripheral waves is regulated by different pathways than the leading edge $[38,39]$. These findings suggest that in OECs, both the leading edge and peripheral lamellipodial waves are involved in initiating cell-cell contact and promote migration.

Time lapse microscopy studies have shown that OECs exhibit a dramatic ability to rapidly change size, morphology and direction of migration over time [38, 45] (fig. 3) and it would appear that lamellipodial protrusions are crucial for all these processes. OECs with a bipolar morphology migrate faster than OECs with a flattened morphology [43], but it remains largely unknown how OEC morphology relates to the ability to initiate cell-cell interactions. When grown in vitro, the interactions between OECs can lead to various arrangements of the cells. For example, bipolar peripheral OECs that initiate interactions via lamellipodial waves (arrows, fig. 3e) tend to adhere to each other and thus continue interacting. This can lead to small chains of OECs forming (fig. 3f) and then with increased migration lead to a uniform mass of OECs that are clearly migrating in the same direction (fig. 3g). Alternatively, different culture conditions may lead to bipolar and flattened OECs mixing together without any apparent directional preference for migration 
(fig. 3h). The different mechanisms that regulate the interaction and migration of the OECs remain unknown, and thus the next research challenges in the field include a detailed characterization of how OEC morphology relates to cellular behaviour. In particular, it is important to determine the molecular mechanisms that enable the leading edge and peripheral lamellipodial waves to respond to guidance cues in distinct subpopulations of OECs.

\section{Organised OEC Migration Enhances Axon Regeneration}

Using in vitro cocultures of OECs and neonatal primary olfactory neurons [40], we have recently shown that OECs always migrate ahead of extending primary olfactory neurons $[22,41]$. We have also demonstrated that a GNDF-mediated increase in lamellipodial wave activity and subsequent OEC migration rate leads to faster axonal extension. Furthermore, we showed that lamellipodial waves in OECs are almost always present at the site of OEC-axon interaction, and that growth cones increase in size when in contact with OEC waves [41]. These findings suggest that the migration of OECs is directly related to the rate of olfactory axon growth, and that lamellipodial waves in OECs are crucial for interactions with olfactory neurons.

We have also investigated how the migration of OECs influences axon extension during regeneration of the olfactory system in vivo. When unilateral bulbectomy was performed followed by administration of methimazole to delay axon regeneration, the OECs migrated into the injury site ahead of the axons [22]. This resulted in the formation of a permissive glial environment that not only dramatically enhanced the growth of olfactory axons, but also resulted in axons projecting in large fascicles and terminating together in distinct well-formed structures. In comparison, in bulbectomised animals where axonal growth was not delayed, there was limited growth of axons and while the axons did form some fascicles they were less distinct. We also confirmed in vitro that olfactory axon extension is more rapid when OECs are widely distributed over a larger area than the axons [22]. Because delayed axonal growth resulted in a more growth-permissive environment, we investigated whether the presence of olfactory axons altered the migratory behaviour of OECs. We found that OECs migrate considerably faster in the absence than in the presence of olfactory axons [22].
The ability of OECs to migrate more rapidly in the absence of axons is similar to the response of Schwann cells following peripheral nerve injury. It has been shown that the migration of Schwann cells is significantly increased when a predenervated nerve graft containing Schwann cells, but not axons, is provided [68]. In this situation the Schwann cells encountered a glial environment that was free of axons, and it is therefore possible that the increased migration of Schwann cells occurred, at least partially, in a similar manner to the OECs in which higher migration occurred in the absence of axons. Thus, delayed axonal growth appears to increase the migration rate of OECs, ultimately leading to superior axonal extension and fascicle formation.

In other injury models, it has previously been reported that when olfactory nerve transection is performed, the OECs do not respond dramatically but instead remain in place and continue to provide conduits for the new growing axons [61]. In contrast, following bulbectomy when the inhibitory cues or physical barriers which restricted OEC movement or proliferation are removed, the OECs rapidly respond by filling the space left by bulbectomy. Thus, it is clear that OECs are not merely providing static support for axons, but are instead able to dynamically respond to a changing environment with the responses varying depending on the situation.

\section{Why Are OECs Suitable for Neural Repair Therapies?}

Following injury to the central nervous system, axons often sprout and regrow but cannot reach their targets due to inflammation, inhibitory cues or physical barriers. Neural repair therapies need to address these problems to create an environment that is conducive to axon growth. One approach for neural repair is to use transplanted glial cells to help stabilise the injury site and to provide an amenable cellular bridge for the axon growth.

The majority of trials using glial cells have used Schwann cells, OECs or combinations of both. Schwann cells enwrap and myelinate individual axons after transplantation [69] but do not integrate well within the central nervous system [70,71]. OECs on the other hand wrap up groups of unmyelinated axons and can integrate well in both the peripheral nervous system and central nervous system since they are naturally present in the primary olfactory nervous system at the peripheral-central nervous system interface. It is possible that transplanted OECs are able to myelinate axons in the right conditions [72] but other studies suggest that it does not occur [69]. 
OECs have been trialled for neural regeneration with some promising results. In humans, a phase I clinical trial of spinal cord injury repair demonstrated that transplantation of autologous OECs is feasible and safe $[73,74]$. In preclinical animal trials, it has been shown that transplanted OECs can survive and migrate within the injured spinal cord of rats $[16,75]$, reduce scar and cavity formation [76, 77], lead to improved functional locomotor and hindlimb recovery $[78,79]$ and can restore breathing and climbing ability [80] even after complete transection of the spinal cord [79, 81]. Similarly, Schwann cells have been shown to promote axon growth in spinal injury models [82] although they are not always as effective as OECs [83]. OECs have also shown promise for transplantation therapies in other areas than the spinal cord. For example, transplanted OECs can migrate along the optic nerve where they can ensheathe retinal ganglion cell axons [84] and have restored sensory input in the injured brachial plexus [85].

The use of growth factors and other cell types in combination with glia has also been trialled. In an optic nerve injury model, OECs together with soluble GDNF have been shown to enhance axon regeneration although the mechanism by which GDNF acted was not investigated [86]. Alternatively, OECs can be genetically engineered to express GDNF to promote nerve repair [50]. In spinal injury transplant therapies, OECs have been introduced as cell suspensions or in matrices into the injury site where they disperse and integrate with the host tissue [16, 87]. Unfortunately they do not maintain a high degree of cellcell contact with each other and therefore do not form a continuous uniform mass. Instead, the OECs tend to be interspersed amongst other cells and remain in close association with axons $[87,88]$. As described above, we have previously shown in an injury model in vivo that in the absence of axons, OECs rapidly form an extensive uniform mass and that the presentation of OECs in this format results in subsequent superior axon growth [22]. It would therefore be of interest to examine whether the delivery of OECs that would encourage their migration as a uniform mass within spinal transplant models would result in improved axon growth.

The variations in the neuro-anatomical and functional outcomes in the different neural repair models can be attributed in part to the source of the OECs and the purification methods used in the trials. Not surprisingly, each laboratory optimises their own dissection, purification and culturing protocols with the result that there are almost as many different preparations of OECs as there are models of neural injury into which the OECs are trans- planted. For example, OECs can be purified from either the peripheral or the central nervous system regions of the olfactory system [89]. 'Central OECs' used for transplantation therapies are often acquired from the entire NFL of the olfactory bulb, which may, or may not, include OECs from both the inner and outer NFLs [90-92]. However, other studies have used central OECs without specifying the topographical locations from which they were obtained [93] or have used a more restricted population of central OECs such as the rostral region of the olfactory bulb [94] or the ventral olfactory bulb [95]. 'Peripheral OECs' from the lamina propria underlying the olfactory epithelium lining the nasal cavity have also been used [77], particularly as they have relevance to human trials due to their accessibility within the nasal cavity $[73-75,78,96]$.

Isolating OECs from the mucosa or bulb requires separation from the many potential 'contaminating' cells. However, it may be that OECs in combination with other cells provide superior outcomes. When OECs had been transplanted together with olfactory nerve fibroblasts, they formed an effective bridge for growth of axons across an injured corticospinal tract [97] and enhanced regeneration of nigrostriatal dopaminergic axons [93]. A recent study demonstrated that fibroblasts can dramatically alter the behaviour of Schwann cells by secreting ephrin B molecules which act on EphB2 receptors in Schwann cells [98]. This study showed that after nerve transection, the presence of fibroblasts promotes Schwann cell sorting followed by contact-mediated directional Schwann cell migration out of the nerve stump, resulting in axonal regrowth across the wound [98]. Thus, the possibility exists that fibroblasts may also alter the behaviour of other glia, including OECs. Within the olfactory system, OECs together with fibroblasts form channels through which axons extend [61], and when grown in vitro fibroblasts promote the proliferation of OECs derived from the olfactory bulb [99]. When OECs had been transplanted together with olfactory nerve fibroblasts, they formed an effective bridge for growth of axons across an injured corticospinal tract [97] and enhanced regeneration of nigrostriatal dopaminergic axons [93]. Transplantation of OECs has also been shown to stimulate migration of endogenous Schwann cells [77]. Thus, not only do we need to consider the source of the OECs, but also their interaction with other cells. Improvements in the use of OECs for neural repair therapies are likely to require a combinatorial approach in which the appropriate subpopulation of OECs together with other cells such as fibroblasts and growth factors are used to optimise OEC interactions and migration and hence promote subsequent axon extension. 


\section{Conclusion}

In summary, OECs are crucial to the development and regeneration of the olfactory system and offer excellent potential for neural repair therapies. However, it is clear that distinct subpopulations of OECs exist with demonstrated heterogeneity in morphology, molecular expression and function. The characteristics of the subpopulations of OECs vary depending on the different regions of the olfactory system in which the OECs are located, the developmental stages and, for in vitro growth, the different culture conditions. These are all variables that need to be considered when contemplating the role of OECs in the olfactory system and when using OECs for transplantation in neural repair therapies. While some recent advances have been made in determining how OECs re- spond to guidance cues at the cellular level, it is clear that what is now needed is a systematic analysis to determine the differences in the molecular and cellular characteristics of the various subpopulations of OECs. This will provide increased understanding of the role of OECs within the olfactory system and will pave the way for improving the use of these cells for transplantation therapies.

\section{Acknowledgements}

This work was supported by a grant from the National Health and Medical Research Council to J.S (grant No. 511006), by funding to the National Centre for Adult Stem Cell Research from the Australian Government Department of Health and Aging to A.M.S, by an Australian Research Council Postdoctoral Fellowship to J.E and an Australian Postgraduate Award to D.A.

\section{References}

1 Graziadei PP, Monti Graziadei GA: Neurogenesis and neuron regeneration in the olfactory system of mammals. I. Morphological aspects of differentiation and structural organization of the olfactory sensory neurons. J Neurocytol 1979;8:1-18.

$\checkmark 2$ Leung CT, Coulombe PA, Reed RR: Contribution of olfactory neural stem cells to tissue maintenance and regeneration. Nat Neurosci 2007;10:720-726.

3 Mackay-Sim A, Kittel P: Cell dynamics in the adult mouse olfactory epithelium: a quantitative autoradiographic study. J Neurosci 1991;11:979-984.

-4 Graziadei GA, Graziadei PP: Neurogenesis and neuron regeneration in the olfactory system of mammals. II. Degeneration and reconstitution of the olfactory sensory neurons after axotomy. J Neurocytol 1979;8:197_ 213.

5 Graziadei PP, Karlan MS, Graziadei GA, Bernstein JJ: Neurogenesis of sensory neurons in the primate olfactory system after section of the fila olfactoria. Brain Res 1980; 186:289-300.

6 Chuah MI, Zheng DR: The human primary olfactory pathway: fine structural and cytochemical aspects during development and in adults. Microsc Res Technique 1992;23:7685.

7 Key B, St John J: Axon navigation in the mammalian primary olfactory pathway: where to next? Chem Senses 2002;27:245260.

8 Doucette JR: Glial influences on axonal growth in the primary olfactory system. Glia 1990;3:433-449.
-9 Buck L, Axel R: A novel multigene family may encode odorant receptors: a molecular basis for odor recognition. Cell 1991;65:175187.

10 Mombaerts P, Wang F, Dulac C, Chao SK, Nemes A, Mendelsohn M, Edmondson J, Axel R: Visualizing an olfactory sensory map. Cell 1996;87:675-686.

11 Doucette JR: Development of the nerve fiber layer in the olfactory bulb of mouse embryos. J Comp Neurol 1989;285:514-527.

12 Barraud P, Seferiadis AA, Tyson LD, Zwart MF, Szabo-Rogers HL, Ruhrberg C, Liu KJ, Baker CV: Neural crest origin of olfactory ensheathing glia. Proc Natl Acad Sci USA 2010;107:21040-21045.

13 Forni PE, Taylor-Burds C, Melvin VS, Williams T, Wray S: Neural crest and ectodermal cells intermix in the nasal placode to give rise to GNRH-1 neurons, sensory neurons, and olfactory ensheathing cells. J Neurosci 2011; 31:6915-6927.

14 Hinds JW: Early neuron differentiation in the mouse olfactory bulb. II. Electron microscopy. J Comp Neurol 1972;146:253-276.

15 Whitesides JG 3rd, LaMantia AS: Differential adhesion and the initial assembly of the mammalian olfactory nerve. J Comp Neurol 1996;373:240-254.

16 Boruch AV, Conners JJ, Pipitone M, Deadwyler G, Storer PD, Devries GH, Jones KJ: Neurotrophic and migratory properties of an olfactory ensheathing cell line. Glia 2001; 33:225-229.

17 Chuah MI, Choi-Lundberg D, Weston S, Vincent AJ, Chung RS, Vickers JC, West AK: Olfactory ensheathing cells promote collateral axonal branching in the injured adult rat spinal cord. Exp Neurol 2004;185:15-25.
18 Chung RS, Woodhouse A, Fung S, Dickson TC, West AK, Vickers JC, Chuah MI: Olfactory ensheathing cells promote neurite sprouting of injured axons in vitro by direct cellular contact and secretion of soluble factors. Cell Mol Life Sci 2004;61:1238-1245.

19 Kafitz KW, Greer CA: Olfactory ensheathing cells promote neurite extension from embryonic olfactory receptor cells in vitro. Glia 1999;25:99-110.

20 Tisay KT, Key B: The extracellular matrix modulates olfactory neurite outgrowth on ensheathing cells. J Neurosci 1999;19:98909899.

21 Woodhall E, West AK, Chuah MI: Cultured olfactory ensheathing cells express nerve growth factor, brain-derived neurotrophic factor, glia cell line-derived neurotrophic factor and their receptors. Brain Res Mol Brain Res 2001;88:203-213.

22 Chehrehasa F, Windus LC, Ekberg JA, Scott SE, Amaya D, Mackay-Sim A, St John JA: Olfactory glia enhance neonatal axon regeneration. Mol Cell Neurosci 2010;45:277-288.

23 Tennent R, Chuah MI: Ultrastructural study of ensheathing cells in early development of olfactory axons. Brain Res Dev Brain Res 1996;95:135-139.

24 Valverde F, Santacana M, Heredia M: Formation of an olfactory glomerulus: morphological aspects of development and organization. Neuroscience 1992;49:255-275.

25 Jessen KR, Mirsky R: The origin and development of glial cells in peripheral nerves. Nat Rev Neurosci 2005;6:671-682.

26 Treloar HB, Feinstein P, Mombaerts P, Greer CA: Specificity of glomerular targeting by olfactory sensory axons. J Neurosci 2002;22: 2469-2477. 
27 Royal SJ, Key B: Development of p2 olfactory glomeruli in $\mathrm{p} 2$-internal ribosome entry sitetau-lacz transgenic mice. J Neurosci 1999;19: 9856-9864.

-28 Au WW, Treloar HB, Greer CA: Sublaminar organization of the mouse olfactory bulb nerve layer. J Comp Neurol 2002;446:68-80.

-29 Au E, Roskams AJ: Olfactory ensheathing cells of the lamina propria in vivo and in vitro. Glia 2003;41:224-236.

-30 Gong Q, Shipley MT: Expression of extracellular matrix molecules and cell surface molecules in the olfactory nerve pathway during early development. J Comp Neurol 1996;366: $1-14$.

-31 Ubink R, Hokfelt T: Expression of neuropeptide $\mathrm{Y}$ in olfactory ensheathing cells during prenatal development. J Comp Neurol 2000; 423:13-25.

- 32 Crandall JE, Dibble C, Butler D, Pays L, Ahmad N, Kostek C, Puschel AW, Schwarting GA: Patterning of olfactory sensory connections is mediated by extracellular matrix proteins in the nerve layer of the olfactory bulb. J Neurobiol 2000;45:195-206.

- 33 Schwarting GA, Kostek C, Ahmad N, Dibble C, Pays L, Puschel AW: Semaphorin 3a is required for guidance of olfactory axons in mice. J Neurosci 2000;20:7691-7697.

-34 St John JA, Key B: Expression of galectin-1 in the olfactory nerve pathway of rat. Brain Res Dev Brain Res 1999;117:171-178.

-35 Rela L, Bordey A, Greer CA: Olfactory ensheathing cell membrane properties are shaped by connectivity. Glia 2010;58:665678.

-36 St John JA, Key B: Chemically and morphologically identifiable glomeruli in the rat olfactory bulb. J Comp Neurol 2001;436:497507.

- 37 Potter SM, Zheng C, Koos DS, Feinstein P, Fraser SE, Mombaerts P: Structure and emergence of specific olfactory glomeruli in the mouse. J Neurosci 2001;21:9713-9723.

- 38 Windus LC, Claxton C, Allen CL, Key B, St John JA: Motile membrane protrusions regulate cell-cell adhesion and migration of olfactory ensheathing glia. Glia 2007;55:17081719.

-39 Windus LC, Lineburg KE, Scott SE, Claxton C, Mackay-Sim A, Key B, St John JA: Lamellipodia mediate the heterogeneity of central olfactory ensheathing cell interactions. Cell Mol Life Sci 2010;67:1735-1750.

-40 Ekberg JA, Amaya D, Chehrehasa F, Lineburg K, Claxton C, Windus LC, Key B, Mackay-Sim A, St John JA: OMP-ZsGreen fluorescent protein transgenic mice for visualisation of olfactory sensory neurons in vivo and in vitro. J Neurosci Methods 2011;196: $88-98$.

41 Windus LC, Chehrehasa F, Lineburg KE, Claxton C, Mackay-Sim A, Key B, St John JA: Stimulation of olfactory ensheathing cell motility enhances olfactory axon growth. Cell Mol Life Sci 2011;68:3233-3247.
42 Pixley SK: The olfactory nerve contains two populations of glia, identified both in vivo and in vitro. Glia 1992;5:269-284.

43 Huang ZH, Wang Y, Cao L, Su ZD, Zhu YL, Chen YZ, Yuan XB, He C: Migratory properties of cultured olfactory ensheathing cells by single-cell migration assay. Cell Res 2008; 18:479-490.

44 Vincent AJ, West AK, Chuah MI: Morphological plasticity of olfactory ensheathing cells is regulated by cAMP and endothelin-1. Glia 2003;41:393-403.

45 Van Den Pol AN, Santarelli JG: Olfactory ensheathing cells: time lapse imaging of cellular interactions, axonal support, rapid morphologic shifts, and mitosis. J Comp Neurol 2003;458:175-194.

46 Cao L, Su Z, Zhou Q, Lv B, Liu X, Jiao L, Li Z, Zhu Y, Huang Z, Huang A, He C: Glial cell line-derived neurotrophic factor promotes olfactory ensheathing cells migration. Glia 2006;54:536-544.

-47 Huang ZH, Wang Y, Su ZD, Geng JG, Chen YZ, Yuan XB, He C: Slit-2 repels the migration of olfactory ensheathing cells by triggering $\mathrm{Ca}^{2+}$-dependent cofilin activation and RhoA inhibition. J Cell Sci 2011;124:186197.

-48 Su Z, Cao L, Zhu Y, Liu X, Huang Z, Huang A, He C: Nogo enhances the adhesion of olfactory ensheathing cells and inhibits their migration. J Cell Sci 2007;120:1877-1887.

49 Vukovic J, Ruitenberg MJ, Roet K, Franssen E, Arulpragasam A, Sasaki T, Verhaagen J, Harvey AR, Busfield SJ, Plant GW: The glycoprotein fibulin-3 regulates morphology and motility of olfactory ensheathing cells in vitro. Glia 2009;57:424-443.

50 Cao L, Liu L, Chen ZY, Wang LM, Ye JL, Qiu $\mathrm{HY}, \mathrm{Lu} \mathrm{CL}, \mathrm{He} \mathrm{C}$ : Olfactory ensheathing cells genetically modified to secrete GDNF to promote spinal cord repair. Brain 2004;127: 535-549.

51 Underwood CK, Coulson EJ: The p75 neurotrophin receptor. Int J Biochem Cell Biol 2008;40:1664-1668.

52 Lipson AC, Widenfalk J, Lindqvist E, Ebendal T, Olson L: Neurotrophic properties of olfactory ensheathing glia. Exp Neurol 2003; 180:167-171

53 Miragall F, Kadmon G, Schachner M: Expression of L1 and N-CAM cell adhesion molecules during development of the mouse olfactory system. Dev Biol 1989;135:272286.

54 Moreno-Flores MT, Lim F, Martin-Bermejo MJ, Diaz-Nido J, Avila J, Wandosell F: Immortalized olfactory ensheathing glia promote axonal regeneration of rat retinal ganglion neurons. J Neurochem 2003;85:861871.

55 Scotti AL, Hoffmann MC, Nitsch C: The neurite growth promoting protease nexin 1 in glial cells of the olfactory bulb of the gerbil: an ultrastructural study. Cell Tissue Res 1994;278:409-413.
56 Mackay-Sim A, Chuah MI: Neurotrophic factors in the primary olfactory pathway. Prog Neurobiol 2000;62:527-559.

57 Wewetzer K, Verdu E, Angelov DN, Navarro $\mathrm{X}$ : Olfactory ensheathing glia and Schwann cells: two of a kind? Cell Tissue Res 2002;309: 337-345.

-58 DeLucia TA, Conners JJ, Brown TJ, Cronin $\mathrm{CM}$, Khan T, Jones KJ: Use of a cell line to investigate olfactory ensheathing cell-enhanced axonal regeneration. Anat Rec B New Anat 2003;271:61-70.

59 Hsu P, Yu F, Feron F, Pickles JO, Sneesby K, Mackay-Sim A: Basic fibroblast growth factor and fibroblast growth factor receptors in adult olfactory epithelium. Brain Res 2001; 896:188-197.

60 Yan H, Nie X, Kocsis JD: Hepatocyte growth factor is a mitogen for olfactory ensheathing cells. J Neurosci Res 2001;66:698-704.

61 Li Y, Field PM, Raisman G: Olfactory ensheathing cells and olfactory nerve fibroblasts maintain continuous open channels for regrowth of olfactory nerve fibres. Glia 2005;52:245-251.

62 Lakatos A, Barnett SC, Franklin RJ: Olfactory ensheathing cells induce less host astrocyte response and chondroitin sulphate proteoglycan expression than Schwann cells following transplantation into adult CNS white matter. Exp Neurol 2003;184:237-246.

63 Fairless R, Frame MC, Barnett SC: N-cadherin differentially determines Schwann cell and olfactory ensheathing cell adhesion and migration responses upon contact with astrocytes. Mol Cell Neurosci 2005;28:253263.

64 Rodriguez-Gil DJ, Greer CA: Wnt/frizzled family members mediate olfactory sensory neuron axon extension. J Comp Neurol 2008; 511:301-317.

65 Imaizumi T, Lankford KL, Waxman SG Greer CA, Kocsis JD: Transplanted olfactory ensheathing cells remyelinate and enhance axonal conduction in the demyelinated dorsal columns of the rat spinal cord. J Neurosci 1998;18:6176-6185.

66 Steketee MB, Tosney KW: Three functionally distinct adhesions in filopodia: shaft adhesions control lamellar extension. J Neurosci 2002;22:8071-8083.

67 Thomas LA, Yamada KM: Contact stimulation of cell migration. J Cell Sci 1992;103: 1211-1214.

68 Tomita K, Hata Y, Kubo T, Fujiwara T, Yano $\mathrm{K}$, Hosokawa K: Effects of the in vivo predegenerated nerve graft on early Schwann cell migration: quantitative analysis using S100GFP mice. Neurosci Lett 2009;461:36-40.

-69 LiY, Li D, Raisman G: Transplanted Schwann cells, not olfactory ensheathing cells, myelinate optic nerve fibres. Glia 2007;55:312316. 
70 Andrews MR, Stelzner DJ: Evaluation of olfactory ensheathing and Schwann cells after implantation into a dorsal injury of adult rat spinal cord. J Neurotrauma 2007;24:17731792.

71 Franssen EH, Roet KC, de Bree FM, Verhaagen J: Olfactory ensheathing glia and Schwann cells exhibit a distinct interaction behavior with meningeal cells. J Neurosci Res 2009;87:1556-1564.

-72 Babiarz J, Kane-Goldsmith N, Basak S, Liu K, Young W, Grumet M: Juvenile and adult olfactory ensheathing cells bundle and myelinate dorsal root ganglion axons in culture. Exp Neurol 2011;229:72-79.

-73 Feron F, Perry C, Cochrane J, Licina P, Nowitzke A, Urquhart S, Geraghty T, Mackay-Sim A: Autologous olfactory ensheathing cell transplantation in human spinal cord injury. Brain 2005;128:2951-2960.

-74 Mackay-Sim A, Feron F, Cochrane J, Bassingthwaighte L, Bayliss C, Davies W, Fronek P, Gray C, Kerr G, Licina P, Nowitzke A, Perry C, Silburn PA, Urquhart S, Geraghty $\mathrm{T}$ : Autologous olfactory ensheathing cell transplantation in human paraplegia: a 3 -year clinical trial. Brain 2008;131:23762386.

75 Deng C, Gorrie C, Hayward I, Elston B, Venn M, Mackay-Sim A, Waite P: Survival and migration of human and rat olfactory ensheathing cells in intact and injured spinal cord. J Neurosci Res 2006;83:1201-1212.

-76 Li BC, Li Y, Chen LF, Chang JY, Duan ZX: Olfactory ensheathing cells can reduce the tissue loss but not the cavity formation in contused spinal cord of rats. J Neurol Sci 2011;303:67-74

-77 Ramer LM, Au E, Richter MW, Liu J, Tetzlaff W, Roskams AJ: Peripheral olfactory ensheathing cells reduce scar and cavity formation and promote regeneration after spinal cord injury. J Comp Neurol 2004;473:1-15.

78 Gorrie CA, Hayward I, Cameron N, Kailainathan G, Nandapalan N, Sutharsan R, Wang J, Mackay-Sim A, Waite PM: Effects of human OEC-derived cell transplants in rodent spinal cord contusion injury. Brain Res 2010; 1337:8-20.

-79 Takeoka A, Jindrich DL, Munoz-Quiles C, Zhong $\mathrm{H}$, van den Brand $\mathrm{R}$, Pham DL, Ziegler MD, Ramon-Cueto A, Roy RR, Edgerton VR, Phelps PE: Axon regeneration can facilitate or suppress hindlimb function after olfactory ensheathing glia transplantation. J Neurosci 2011;31:4298-4310.
80 Li Y, Decherchi P, Raisman G: Transplantation of olfactory ensheathing cells into spinal cord lesions restores breathing and climbing. J Neurosci 2003;23:727-731.

81 Ziegler MD, Hsu D, Takeoka A, Zhong H, Ramon-Cueto A, Phelps PE, Roy RR, Edgerton VR: Further evidence of olfactory ensheathing glia facilitating axonal regeneration after a complete spinal cord transection. Exp Neurol 2011;229:109-119.

82 Garcia-Alias G, Lopez-Vales R, Fores J, Navarro X, Verdu E: Acute transplantation of olfactory ensheathing cells or Schwann cells promotes recovery after spinal cord injury in the rat. J Neurosci Res 2004;75:632-641.

3 Keyvan-Fouladi N, Raisman G, Li Y: Delayed repair of corticospinal tract lesions as an assay for the effectiveness of transplantation of Schwann cells. Glia 2005;51:306-311.

84 Li Y, Li D, Khaw PT, Raisman G: Transplanted olfactory ensheathing cells incorporated into the optic nerve head ensheathe retinal ganglion cell axons: possible relevance to glaucoma. Neurosci Lett 2008;440:251-254.

85 Ibrahim AG, Kirkwood PA, Raisman G, Li Y: Restoration of hand function in a rat model of repair of brachial plexus injury. Brain 2009;132:1268-1276.

86 Liu Y, Gong Z, Liu L, Sun H: Combined effect of olfactory ensheathing cell (OEC) transplantation and glial cell line-derived neurotrophic factor (GDNF) intravitreal injection on optic nerve injury in rats. Mol Vis 2010; 16:2903-2910.

87 Sasaki H, Berlin R, Baker H: Transient expression of tyrosine hydroxylase promoter/ reporter gene constructs in the olfactory epithelium of transgenic mice. J Neurocytol 2004;33:681-692.

88 Ruitenberg MJ, Plant GW, Christensen CL, Blits B, Niclou SP, Harvey AR, Boer GJ, Verhaagen J: Viral vector-mediated gene expression in olfactory ensheathing glia implants in the lesioned rat spinal cord. Gene Ther 2002;9:135-146.

89 Richter MW, Roskams AJ: Olfactory ensheathing cell transplantation following spinal cord injury: hype or hope? Exp Neurol 2008;209:353-367.
90 Li Y, Field PM, Raisman G: Repair of adult rat corticospinal tract by transplants of olfactory ensheathing cells. Science 1997;277: 2000-2002.

91 Lopez-Vales R, Fores J, Verdu E, Navarro X: Acute and delayed transplantation of olfactory ensheathing cells promote partial recovery after complete transection of the spinal cord. Neurobiol Dis 2006;21:57-68.

92 Ramon-Cueto A: Olfactory ensheathing glia transplantation into the injured spinal cord. Prog Brain Res 2000;128:265-272.

-93 Teng X, Nagata I, Li HP, Kimura-Kuroda J, Sango K, Kawamura K, Raisman G, Kawano $\mathrm{H}$ : Regeneration of nigrostriatal dopaminergic axons after transplantation of olfactory ensheathing cells and fibroblasts prevents fibrotic scar formation at the lesion site. J Neurosci Res 2008;86:3140-3150.

-94 Lankford KL, Sasaki M, Radtke C, Kocsis JD Olfactory ensheathing cells exhibit unique migratory, phagocytic, and myelinating properties in the $\mathrm{X}$-irradiated spinal cord not shared by Schwann cells. Glia 2008;56:16641678.

95 Guest JD, Herrera L, Margitich I, Oliveria M, Marcillo A, Casas CE: Xenografts of expanded primate olfactory ensheathing glia support transient behavioral recovery that is independent of serotonergic or corticospinal axonal regeneration in nude rats following spinal cord transection. Exp Neurol 2008; 212:261-274.

-96 Mackay-Sim A, St John JA: Olfactory ensheathing cells from the nose: clinical application in human spinal cord injuries. Exp Neurol 2011;229:174-180.

-97 Li Y, Field PM, Raisman G: Regeneration of adult rat corticospinal axons induced by transplanted olfactory ensheathing cells. J Neurosci 1998;18:10514-10524.

98 Parrinello S, Napoli I, Ribeiro S, Digby PW, Fedorova M, Parkinson DB, Doddrell RD, Nakayama M, Adams RH, Lloyd AC: EPHB signaling directs peripheral nerve regeneration through Sox2-dependent Schwann cell sorting. Cell 2010;143:145-155.

99 Yui S, Ito D, Fujita N, Nishimura R: Effects of fibroblasts derived from the olfactory bulb and nasal olfactory mucosa on proliferation of olfactory ensheathing cells harvested from the olfactory bulb. J Vet Med Sci 2011; 73:133-137. 